\title{
Modular assessment of the performance of embankment dams
}

\author{
Gisèle Bambara ${ }^{\mathrm{a}, \mathrm{b}, \mathrm{e}^{*},}$ Corinne Curt ${ }^{\mathrm{a}}$, Patrice Mériaux ${ }^{\mathrm{a}}$, Michel Vennetier ${ }^{\mathrm{d}, \mathrm{e}}$ and \\ Pierre Vanloot ${ }^{\mathrm{b}}$ \\ alrstea, UR Ouvrages hydrauliques et Hydrologie, Aix-en-Provence Cedex 5, \\ France; \\ ${ }^{\mathrm{b}}$ Aix-Marseille Université, LISA, Marseille Cedex 20, France; \\ 'Aix-Marseille Université, école doctorale E251, CEREGE Europôle de I'Arbois, \\ Aix en Provence Cedex 4, France; \\ Irstea, UR Ecosystèmes Méditerranéens et Risques, Aix-en-Provence Cedex \\ 5, France; \\ 'Fédération de recherche ECCOREV (FR 3098), Europôle Méditerranéen de \\ I'Arbois, Aix-en-Provence Cedex 4, France
}

(Received 30 July 2015; accepted 16 May 2016)

European Journal of Environmental and Civil Engineering, 2016

http://dx.doi.org/10.1080/19648189.2016.1194322

\begin{abstract}
The performance assessment of embankment dams in respect to main deterioration mechanisms is a major challenge for managers in charge of their security. Curt et al (2010) developed knowledge-based models for assessing the performance of embankment dams. They have three hierarchical levels: performance of the analysed component (embankment, foundations), performance of the functions and status indicators. However, while these dams are frequently located upstream elements at risk, small dams are rarely equipped with drains and monitoring instruments and woody vegetation is often present. These features were partially or not dealt with in the previous models. To cope with them, we propose to firstly, identify the specific status indicators linked with woody vegetation and secondly, adapt and complete the existing models. A modular approach is notably proposed in order to evaluate different types of dam. The approach was applied to a group of seven French and Italian dams and showed its relevance.
\end{abstract}

Keywords: hydraulic works, dams, woody vegetation, performance, knowledge-based system.

\section{Introduction}

There are hundreds of thousands of dams around the world, some of which are several centuries old. The role of these civil engineering works is essential. They can fulfil several functions: irrigation of crops, storage for the distribution of drinking water, leisure, hydropower development schemes and so forth

However a dam breach can have dramatic economic and human consequences, obliging the managers of these structures to take into account and remedy all the possible breach scenarios to ensure that the security of their dams is optimal. Of the mechanisms causing the deterioration of earthfill hydraulic structures such as embankment dams, internal erosion is one of the main causes of breaching (Foster, Fell, \& Spannagle, 2000). It is caused by non-controlled leaks that carry away particles following their detachment. Four mechanisms can be distinguished: concentrated leak, backward erosion piping, contact erosion and suffusion (Deroo \& Fry, 2014). These 
mechanisms can have different origins: structural ageing, poor design/construction, defective maintenance, etc. Thus four main factors can influence the occurrence of a degradation mechanism by internal erosion: the geometry of the structure, its geotechnical characteristics, hydraulics and the "biological" environment (type of vegetation, level of decomposition of root systems, presence of burrowing animals, etc.), all characteristics that can evolve through time due to natural ageing and climatic conditions. These factors of fragility can act on deterioration by internal erosion already installed within the structure and have an impact on its level of security.

Assessing the performance of an embankment dam consists in seeking and assessing all the factors of vulnerability contributing to the occurrence of damage. It allows appreciating, at a given moment, the fitness of a hydraulic structure to fulfil the functions for which it was designed and thus its level of safety. Finally, this assessment permits managers and owners to take the best decisions for carrying out the maintenance works required to ensure the safety of their structures. In this context, the managers responsible for the safety of dams demand methods and tools that they can use to perform rapid and detailed diagnostics of their structures so they can assess their status and performance.

Different methods exist for assessing the performance of complex systems (Racoceanu, 2006; Zwingelstein, 1995) and dams in particular (Peyras, Royet, Boissier, \& Vergne, 2004): physical modelling, functional modelling, statistical analyses, approaches based on artificial intelligence (Bayesian networks, knowledge-based models, etc.) and multicriteria methods. These different approaches are complementary and can be carried out simultaneously (Peyras et al., 2004). Artificial intelligence based approaches have been applied to diagnose dam safety and assess their performance: neuronal networks (Su, Wu, \& Wen, 2007; Wu \& Su, 2005), Bayesian networks (Liu, $\mathrm{Wu}$, Yang, Hu, \& Xu, 2012; Xu, Zhang, \& Jia, 2011; Zhang, Xu, Jia, \& Zhao, 2011) and knowledge-based systems (Andersen, Chouinard, Hover, \& Cox, 2001; Andersen \& Torrey, 1995; Chou, Chen, Wang, Chen, \& Chen, 2001; Curt, Peyras, \& Boissier, 2010; Curt, 2013). We have chosen to use knowledge based systems: these are especially interesting for assessing the performance of complex systems such as dams as they can reproduce the reasoning of an expert and take into account data of various origins and types (visual observations, design-visualisation data, monitoring data, resulting from models). The works cited above focused on the case of dams (i) equipped with monitoring instruments providing the information required to assess their performance with respect to deterioration mechanisms such as internal erosion; (ii) equipped with a drainage system, one of the components ensuring the safety of these structures. However, certain dams such as embankment dams have specific characteristics on which we intend to focus on here:

- They can be subject to the presence of trees on or at their edges. However, this type of vegetation raises a large number of problems as it can lead to the occurrence of short, medium and long-term degradation mechanisms (FEMA, 2005; Laasonen, 2013; Martinez Santamaria \& Fernandez Serrano, 2010; Mériaux, Vennetier, Aigouy, Hoonakker, \& Zylberblat, 2006), notably internal erosion due to the decomposition of root systems. Our aim is therefore to propose models that take into account this unwanted item in order to make them more realistic.

- Contrary to large dams, they are hardly or not at all equipped with monitoring instruments. The information used to assess the performance of these structures is therefore not readily available. We seek to develop models that can be used with different information according to its 
availability, for example if data resulting from monitoring measures are not available, then it must be possible to replace this information with visual measurements and design and construction data.

- They can be of different types. Indeed, we focus on different types of embankment dam which, according to case, can have various sealing systems, be equipped or not with drainage systems and be monitored or not. We consider the components "embankment" and "foundations". The objective is to develop a minimum number of models for different types of dam by using a modular approach, that is to say by combining preformulated modules.

Although the sizes of these structures are rather small, they are often located directly upstream of sensitive areas (dwellings, cultivated areas, commercial and industrial activities), meaning that their breach would have major consequences. It is therefore important to develop models to assess the performances of this type of structure. At present, only models for assessing the performance of embankment dams with respect to deterioration by internal erosion have been developed so far and it is these models that are presented in this article.

The latter two points imply that the assessment of performance with respect to the mechanism of deterioration by internal erosion can be performed according to a mode that we term "abnormal", meaning that not all the information is available and that the dams are not all equipped with drainage systems. On the contrary, "nominal" mode indicates that the dams are equipped with monitoring instruments and drained. Trees are taken into account in the two modes.

The work was supported by the Alcotra RISBA (RISque des BArrages) project. The structures studied are therefore located in particular in the French-Italian border area. We applied the models to seven French and Italian dams.

Initially, we present the approach adopted to build embankment dam performance assessment models with respect to deterioration by internal erosion. Secondly, we present our results stemming from the identification, formalisation and aggregation of status indicators specific to woody vegetation. The adaptations made to the embankment dam performance assessment models and the modular approach implemented are then defined. Finally, this article presents the applications performed during the study on seven dams on the French-Italian border area.

\section{Approach to building performance assessment models}

The data used to assess a dam stem from different factors relating to their security (geometric, geotechnic, hydraulic and biological) and are of different types (monitoring data, visual data, etc.). The internal erosion mechanism is complex as it involves several components and governed by different dynamics. The models proposed must incorporate these constraints. The modelling approach chosen is a knowledgebased system (Akerkar \& Sajja, 2009; Booker \& McNamara, 2004) as it responds well to the constraints of the problem: visual observations can be used, and these can be combined with different types of information such as construction and monitoring data, visual observations, etc. This type of approach also has the advantage of producing models that can be easily understood by engineers and technicians.

\subsection{Approach}

We use as our basis the models of Curt et al (2010) and Curt (2013) which are adapted to assessing the performance of embankment dams equipped with drainage 
systems and monitoring instruments for both the "embankment" part and the foundation of the structure.

Our approach consists in first analysing these models to show their limits in comparison with our application, then propose modifications and adaptations to take these limits into account. Figure 1 shows the hierarchical model for assessing the performance of an embankment dam with respect to deterioration by internal erosion (Curt, Peyras, \& Boissier, 2010), and the limits of this model.

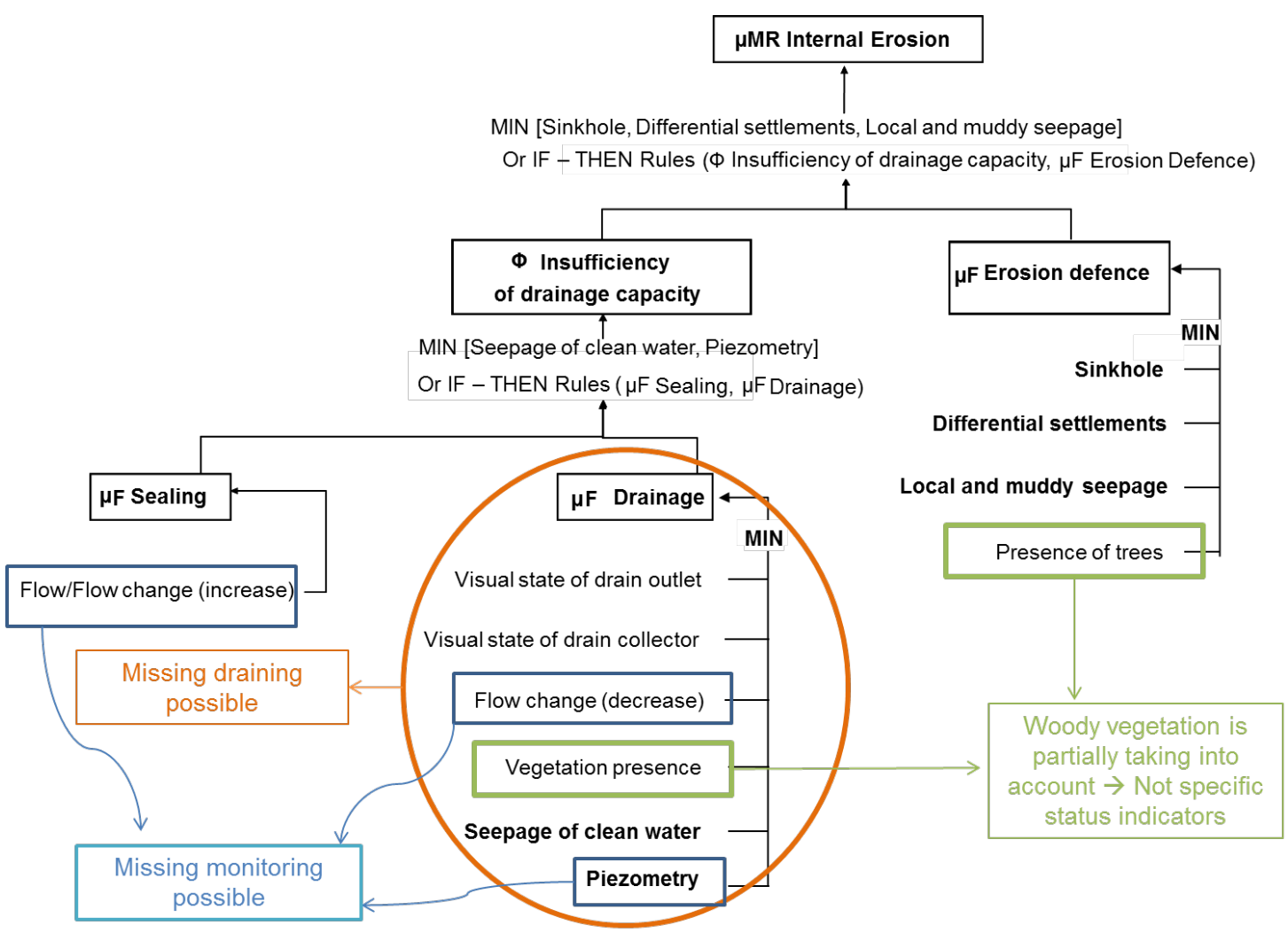

Figure 1. Hierarchical model for assessing an embankment dam built using homogenous fill equipped with a drain and monitoring instruments [ $\mu$ =performance; $\Phi=$ phenomenon] (Curt, Peyras, \& Boissier, 2010)

\subsubsection{Structure of the model}

These assessment models have a three level hierarchical structure: i) status indicators, these are the input data of the model; ii) the performance of functions (for example, the "sealing" function) calculated by combining the values of the status indicators; and iii) the performance of the component (for example, the embankment) regarding the internal erosion mechanism calculated by combining the performance of the functions. The two types of combination are achieved using whether by IF-THEN rules summarised as expert truth tables, or by the mathematical operator Minimum (MIN).

The status indicators are formalised data. Different data are used by the engineer to perform an assessment: monitoring data if the dam is equipped with instruments, visual observations, design and construction data and calculation data (for example, admissible gradient). It is important to formalise them, on the one hand in order to obtain robust measurements, that is to say repeatable and reproducible, and, on the other hand, to use them in combination. Therefore a formalisation grid is used. It is based on five fields: the name of the status indicator, its definition, the scale of measurement and the associated references providing the anchoring points on the scale 
and which allow describing the different possible statuses of the indicator, the spatial characteristics specifying the part of the dam to be analysed and the temporal characteristics indicating the time step for measuring the indicator and the analysis of the trend presented by this measure (Curt, Peyras, \& Boissier, 2010).

We propose using a double assessment scale for all the indicators: an ordinal scale characterised by the ordering of categories as a function of an intensity criterion linked to a scale of intervals that permits working on continuous numerical magnitudes (Figure 2).

Figure 2. Scale of the double assessment chosen for assessing the performance of dams.

\begin{tabular}{cccccccccccc}
\hline unacceptable & \multicolumn{3}{c}{ Bad } & & \multicolumn{3}{c}{ Poor } & \multicolumn{2}{c}{ acceptable } & \multicolumn{2}{c}{ Good at very good } \\
\hline 0 & 1 & 2 & 3 & 4 & 5 & 6 & 7 & 8 & 9 & 10
\end{tabular}

To build our model we conserve this general structure according to three levels: status indicator, performance of functions and the performance of the component regarding the deterioration mechanism.

\subsubsection{The limits of existing models}

The limits of these existing models with respect to the dams dealt with here stem from the fact that they were developed for embankment dams equipped with drainage systems and monitoring devices. This observation leads us to propose three adaptations.

As shown in Figure 1, the performance of the embankment of a dam regarding the mechanism of deterioration by internal erosion is assessed using three function performances: the sealing function, the drainage function and the self-filtration function. The performance of the drainage function cannot be assessed if the structure is not equipped with a drainage system. The structure of the model must be modified to offset this shortcoming.

Each of the performances is assessed on the basis of status indicators stemming in part from monitoring data: "increased flow rate", "piezometry", etc. However, this type of information is not always available for the structures we wish to study, thus the aim is to propose other information possibly available to experts, notably design and construction data.

Lastly, the small embankment dams studied here are often, or have been, subject to a lack of maintenance that has led to abundant woody vegetation on or at the edges of the embankments. The existing models consider woody vegetation only for assessing the performance of the drainage function and the self-filtration function using a single status indicator termed "presence of woody vegetation". Indeed, they consider only the assessment of the performance of embankment dams regarding the mechanism of deterioration by internal erosion by suffusion. However, we want to assess the performance of embankment dams regarding other internal erosion mechanisms, including in particular the internal concentrated leak erosion mechanism which may occur due to the presence of decomposing woody roots. It is therefore important to characterise this vegetation in greater detail by developing specific status indicators that permit assessing the potential for internal erosion of an earthfill hydraulic structure due to the state of the woody vegetation present on the dam (tree density, level of decomposition of root systems of dead trees, etc.). Furthermore, the presence of vegetation leads to another improvement to the models: the components assessed are, as for the existing models, the embankment and the foundation of the dam, but the embankment-foundation interface must be considered specifically in the case of a dam 
that has no drainage system, as this zone can be a preferential location for the installation of woody roots.

The following steps of the approach are aimed at proposing methods to respond to these three main constraints (possible absence of a drainage system, possible absence of monitoring data, presence of woody vegetation).

\subsection{Proposal of specific indicators for woody vegetation}

We used the safety assessment techniques (Functional Analysis - FA - and Failure Mode and Effects Analysis - FMEA) to identify the indicators specific to woody vegetation by focusing on the external element "woody vegetation". The FA is carried out in two steps. An external FA makes it possible, initially, to identify the function(s) that the structure must have regarding external constraints, in this case woody vegetation. An internal FA is then performed. It leads to the identification of different functions resulting from the relations between each component of the structure and the external environment. It therefore permits formulating the functions of each component: the contact and flow function (Zwingelstein, 1996). Following the FA, an FMEA is used to identify the failure modes, their effects and possible causes for each component, and the indicators of the causes and effects of the failures of the different components. This inductive method systematically considers each component of the structure, one after the other. In our case, the failure mode considered is internal erosion linked to the presence of vegetation.

On the basis of these elements, knowledge collection and formalisation sessions are organised with a group of three engineers acknowledged to be expert in hydraulic structures founded on the knowledge and knowhow characterising the expertise (Zwingelstein, 1995). One of these expert engineers was also competent in forestry and had been particularly involved for many years in research works on the impact of woody vegetation on hydraulic structures and their associated management resources. The sessions took place on the basis of structured interviews: they were prepared beforehand by the panel coordinator, and documents were presented during the session. The coordinator compiles the knowledge, and formalises and analyses it to identify possible gaps and inconsistencies. These problems are dealt with at the beginning of the following session, after which the collection continues. The formalisation of expert knowledge is validated during this step. The experts use the formalisations on examples of real cases and express their agreement/disagreement regarding the formalisations. The indicators are modified if necessary. The starting point comprises the indicators listed in the FMEA tables. The objective of the sessions is to describe these indicators in order to ensure their robustness for application.

However, it is difficult to assess certain status indicators when there are no known instrumental methods and if visual observation is impossible, since the element to be assessed is inaccessible, as is the case of the status indicator "Degree of decomposition of the woody stump or roots of an individual "." Thus an indirect chemical measure by NIRS (Near Infrared Spectrometry) has been developed (Bambara, Curt, Vennetier, Mériaux, Zanetti \& Vanloot, 2013) and a formalisation for this indicator based on the results of the chemical measurement proposed. To do this, experimental systems composed of samples taken from the roots of freshly cut trees of different diameters and species were installed on "test" embankment dams located in different French geographic areas. Part of the samples was collected about every two years to monitor the evolution of their decomposition by chemical analysis (NIRS) through time.

1 We use the term "individual" for living trees and dead stumps without distinction. 
Author-produced version of the article published in European Journal of Environmental and Civil Engineering, 2016,

The original publication is available at www.tandfonline.com

Doi : 10.1080/19648189.2016.1194322

We used the results of this chemical analysis to establish the references on the scale of assessment used for the indicator.

\subsection{Development of models to assess performance in abnormal mode}

In addition to introducing status indicators specific to woody vegetation in existing models, the models proposed must take into account all the types of dam studied. Potentially, twenty four cases (four sealing systems with and without sealing monitoring devices, with and without drainage systems, and with and without drainage monitoring systems) could be considered for the embankment dam (table 1), leading to the development of 24 models. For example, a dam with a homogenous embankment subject to the presence of woody vegetation, not equipped with a drainage system and not monitored. In parallel, 6 models for the foundation and 10 models for the interface had to be developed, leading to a total of 40 models. 


\begin{tabular}{|c|c|c|c|c|}
\hline Seal type & Seal monitoring & Drainage & $\begin{array}{c}\text { Drainage } \\
\text { monitoring }\end{array}$ & $\begin{array}{c}\text { Cases } \\
\text { number }\end{array}$ \\
\hline \multirow{7}{*}{$\begin{array}{l}\text { Homogeneous } \\
\text { dam }\end{array}$} & \multirow{3}{*}{ Yes } & \multirow{2}{*}{ Yes } & Yes & 1 \\
\hline & & & No & 2 \\
\hline & & No & & 3 \\
\hline & \multirow{3}{*}{ No } & \multirow{2}{*}{ Yes } & Yes & 4 \\
\hline & & & No & 5 \\
\hline & & No & & 6 \\
\hline & \multirow{3}{*}{ Yes } & \multirow[t]{2}{*}{ Yes } & Yes & 7 \\
\hline \multirow{5}{*}{$\begin{array}{c}\text { Dam with } \\
\text { upstream } \\
\text { concrete facing }\end{array}$} & & & No & 8 \\
\hline & & No & & 9 \\
\hline & \multirow{3}{*}{ No } & \multirow{2}{*}{ Yes } & Yes & 10 \\
\hline & & & No & 11 \\
\hline & & No & & 12 \\
\hline \multirow{6}{*}{$\begin{array}{c}\text { Dam with } \\
\text { impervious clay } \\
\text { facing }\end{array}$} & \multirow{3}{*}{ Yes } & \multirow{2}{*}{ Yes } & Yes & 13 \\
\hline & & & No & 14 \\
\hline & & No & & 15 \\
\hline & \multirow{3}{*}{ No } & \multirow{2}{*}{ Yes } & Yes & 16 \\
\hline & & & No & 17 \\
\hline & & No & & 18 \\
\hline \multirow{6}{*}{$\begin{array}{c}\text { Dam with } \\
\text { impervious core }\end{array}$} & \multirow{3}{*}{ Yes } & \multirow{2}{*}{ Yes } & Yes & 19 \\
\hline & & & No & 20 \\
\hline & & No & & 21 \\
\hline & \multirow{3}{*}{ No } & \multirow{2}{*}{ Yes } & Yes & 22 \\
\hline & & & No & 23 \\
\hline & & No & & 24 \\
\hline
\end{tabular}

The types of sealing studied were: dams with a homogenous embankment, with an upstream concrete facing, an impervious clay facing and zoned structures (with an impervious core).

The models of Curt et al (2010) were built according to functional logic: the assessment of performance regarding the mechanism of deterioration by internal erosion was achieved by combining the performance of the functions. This construction permits considering a modular approach: modules were developed to constitute a library and modules pertinent for a given dam were combined when analysing the structure. The advantage of this approach is that it considerably reduces the number of models to be developed while covering every configuration of the structures. 
The functions involved were sealing, drainage and self-filtration (Figure 1). The first step was to adapt a specific module for each modality by taking into account the absence or presence of monitoring systems for these different functions. For example, to assess the sealing function, if no monitoring data is available to estimate the status indicator "Flow/Flow change (increase)" (cf. Figure 1), we use data from the designconstruction file such as "Permeability of material", "Compaction", etc. These data had been formalised and used previously as status indicators to define the "conformity of components to professional practice". However, if the information ("Permeability of material", "Compaction") is incomplete or unavailable, the engineer assesses this indicator according to expert appraisal.

Secondly, an assembly of modules during the assessment of a given dam is performed using a decision tree: if the drainage function is present, the aggregation rules are kept (cf. Figure 1). If the drainage function is absent, new IF-THEN type aggregation rules are defined with the expert group to combine the sealing function with the resistance to internal erosion function to obtain the performance of the component regarding the internal erosion deterioration mechanism.

These modules and aggregations are formalised during the expert sessions.

\subsection{Validations}

A total of seven applications were performed, making it possible to verify the formalisations and aggregations of status indicators as well as the aggregations of function performances to obtain the performance of a component (embankment, embankment-foundation interface, foundation) regarding the internal erosion deterioration mechanism.

Engineers with different levels of experience made visits in the field to score all the indicators required to assess the performance of each structure regarding internal erosion. A file summarising each status indicator and its formalisation grid was provided to them. The scoring was first done by the engineers independently, then consensual scores were determined during discussions between them. The model was used to calculate the performance of the functions, then the performance regarding the internal erosion of each component. In parallel, the experts gave a global score without using the model. This was done to verify that the model developed clearly reflected the opinion of the experts.

The results were then produced with the experts in order to make the final adjustments to the performance assessment models. 
Author-produced version of the article published in European Journal of Environmental and Civil Engineering, 2016, The original publication is available at www.tandfonline.com

Doi : 10.1080/19648189.2016.1194322

\subsection{Synthesis}

Improvements and adaptations were proposed following the analysis of the existing models developed by Curt et al (2010) and Curt (2013) to assess the performance of the smaller dams on which we focus here, notably embankment dams that are frequently

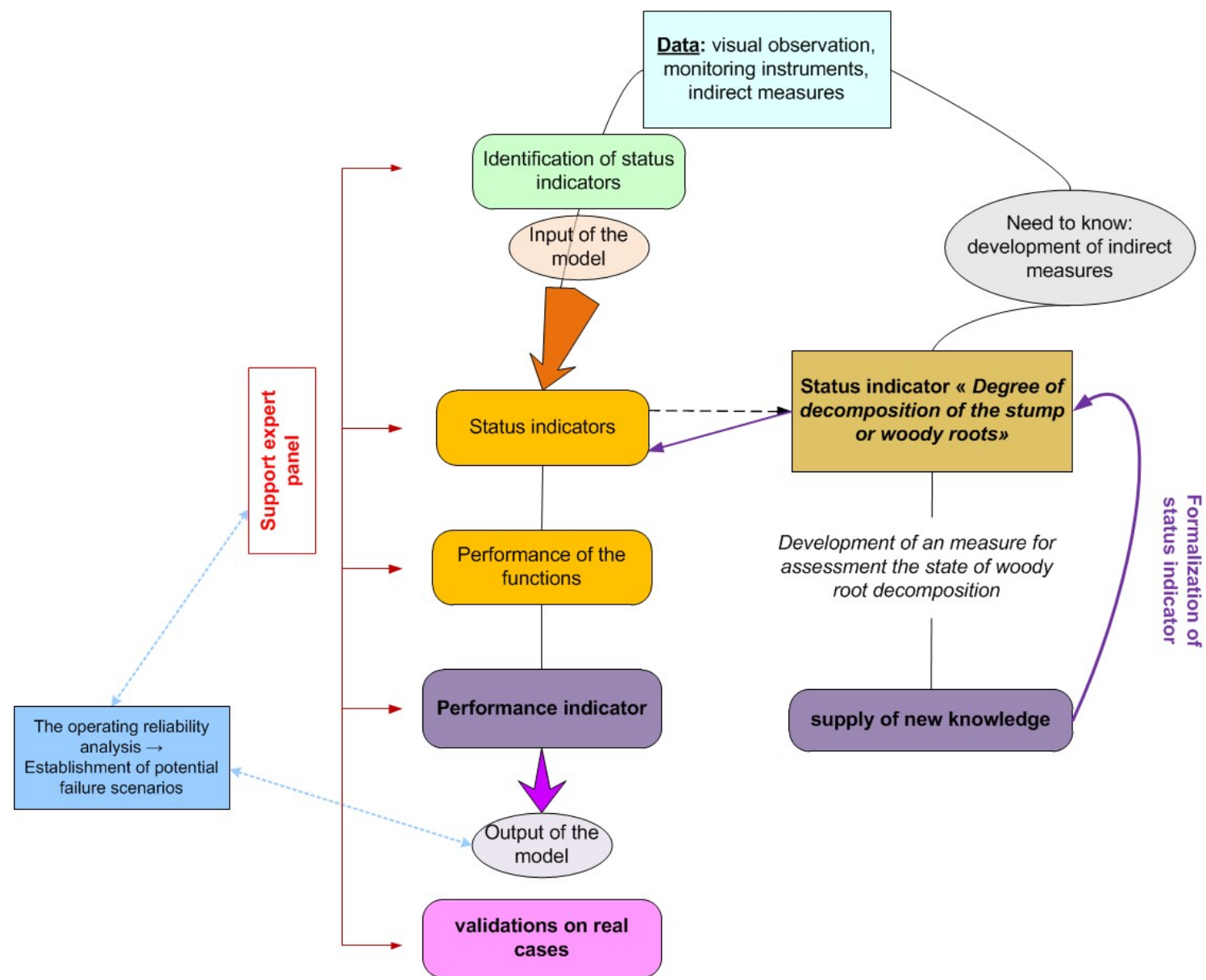

Figure 3. General methodology proposed for building embankment dam performance assessment models. subject to woody vegetation. Figure 3 synthesises the methodology and steps that we adopted.

\section{Identification, formalisation and aggregation of status indicators specific to woody vegetation}

Five specific status indicators were identified as necessary to assess the performance of embankment dams regarding the mechanism of deterioration by internal erosion due to the presence of woody vegetation. These status indicators were identifies using an FMEA. The table 2 is an extract from the FMEA table made for the identification of specific indicators for woody vegetation. 
Table 2. Extract of the FMEA table for embankment component.

\begin{tabular}{|c|c|c|c|c|c|c|}
\hline Component & Function & $\begin{array}{l}\text { Failure } \\
\text { mode }\end{array}$ & $\begin{array}{c}\text { Possible } \\
\text { causes of } \\
\text { failure }\end{array}$ & $\begin{array}{c}\text { Possible } \\
\text { effects of } \\
\text { failure }\end{array}$ & Indicators & $\begin{array}{l}\text { Detecting } \\
\text { means }\end{array}$ \\
\hline $\begin{array}{c}\text { Embankmen } \\
\mathrm{t}\end{array}$ & $\begin{array}{l}\text { Limit the } \\
\text { hydraulic } \\
\text { flow }\end{array}$ & $\begin{array}{c}\text { The } \\
\text { function } \\
\text { « limit } \\
\text { the } \\
\text { hydraulic } \\
\text { flow » is } \\
\text { degraded } \\
\text { or is } \\
\text { failed }\end{array}$ & $\begin{array}{c}\text { Presence of } \\
\text { stumps and } \\
\text { wood roots in } \\
\text { decomposition }\end{array}$ & $\begin{array}{c}\text { Increased } \\
\text { permeability, } \\
\text { heterogeneity } \\
\text { of the } \\
\text { permeability } \\
\text { in the } \\
\text { embankment }\end{array}$ & $\begin{array}{l}\text { Degree of } \\
\text { decomposition } \\
\text { of the stump } \\
\text { or woody } \\
\text { roots of an } \\
\text { individual } \\
\text { (trees and } \\
\text { stumps) }\end{array}$ & $\begin{array}{c}\text { Indirect } \\
\text { measures, } \\
\text { predictive } \\
\text { models }\end{array}$ \\
\hline
\end{tabular}

Four were involved in the assessment of the sealing function ("Density of individuals", "Root volume per individual", "Type of root structure of individuals" and "Degree of decomposition of the stump or woody roots of an individual") and one in the assessment of the drainage function ("Visual condition of the environment of the drainage blanket outlet"). Three of these indicators were assessed visually: "Density of individuals", "Root volume per individual" and "Visual condition of the environment of the outlet of the drainage blanket". The indicator "Type of root structure of individuals" was assessed by using an identification key based on the different parameters influencing the structure of the root system (type of soil, access to water, etc.) adapted from (Zanetti, Vennetier, Mériaux, \& Provansal, 2015). The last indicator "Degree of decomposition of the stump or woody roots of an individual" resulted from an interpretation of an indirect chemical measure (Bambara, Curt, Vennetier, Mériaux, Zanetti \& Vanloot, 2013). The density of individuals present on a structure analysed provides indirect information on the volume occupied by roots in the embankment dam and its edges. The status indicator "Density of individuals" is therefore the first indicator to be taken into account by the engineer. If no individual is present on the structure (score 10), it is not necessary to go to the other status indicators specific to woody vegetation; the models are therefore pertinent even in the absence of vegetation. In table 3, we present the formalisation grid for assessing the indicator "Density of individuals" with the scoring scale of figure 2. 
Table 3. Formalisation grid for the status indicator "Density of individuals".

\begin{tabular}{|c|c|}
\hline Name & Density of individuals \\
\hline Definition & $\begin{array}{l}\text { More the density of tree sis high, more heterogeneities of } \\
\text { permeability in embankment may appear, especially upon root } \\
\text { systems decomposition. We primarily look at the big trees for } \\
\text { this indicator. }\end{array}$ \\
\hline \multirow[t]{4}{*}{ Scale and references } & 10: without individuals \\
\hline & 5-4: presence one individual for $10 \mathrm{~m}^{2}$ of embankment \\
\hline & 3-2: presence to 2 at 5 individuals for $10 \mathrm{~m}^{2}$ of embankment \\
\hline & $\begin{array}{l}\text { 1-0: presence upper at } 5 \text { individuals for } 10 \mathrm{~m}^{2} \text { of embankment } \\
\text { Choice / profile (s) analyzed dam: } 1 \text { profile representative of the }\end{array}$ \\
\hline characteristics & $\begin{array}{l}\text { entire structure with respect to the density of individuals and, if } \\
\text { necessary, one second profile having a worst woody vegetation } \\
\text { density. }\end{array}$ \\
\hline Temporal & Measurement is carried out during a visual examination focused \\
\hline characteristics & on the characterization of woody vegetation on dam. \\
\hline
\end{tabular}

Knowing that root systems grow as a tree ages, an individual with a stump having a large diameter leads to assuming a large root volume per individual. Thus the indicator "Root volume per individual" transposes the measure of the tree root diameter. It is important to know this parameter to predict the impact in terms of the global increase of dam permeability during root system decomposition.

The status indicator "Type of root structure of individuals" provides a global root characterisation next to the profile analysed. Indeed, the different types of root structure of individuals can act on the internal erosion mechanism to varying degrees during woody root decomposition. Thus individuals with a long horizontal type root structure with the potential for crossing the embankment dam from downstream to upstream would be particularly serious. The decomposition of this type of root would likely form a pipe through the embankment (depending on the type of material), hence the importance of having an assessment of the status indicator "Degree of decomposition of the stump or woody roots of an individual".

The status indicator "Visual condition of the environment of the drainage blanket outlet" is appreciated by the "Density of individuals" present at the outlet of the drainage blanket. Thus it has the same references as the status indicator "Density of individuals".

The status indicators specific to woody vegetation are aggregated according to functional logic. Their successive combinations permit obtaining the propensity to flows within the embankment dam due to the presence of vegetation (Figure 4). This "block" will be used for assessing the performance of the sealing function. 
4.

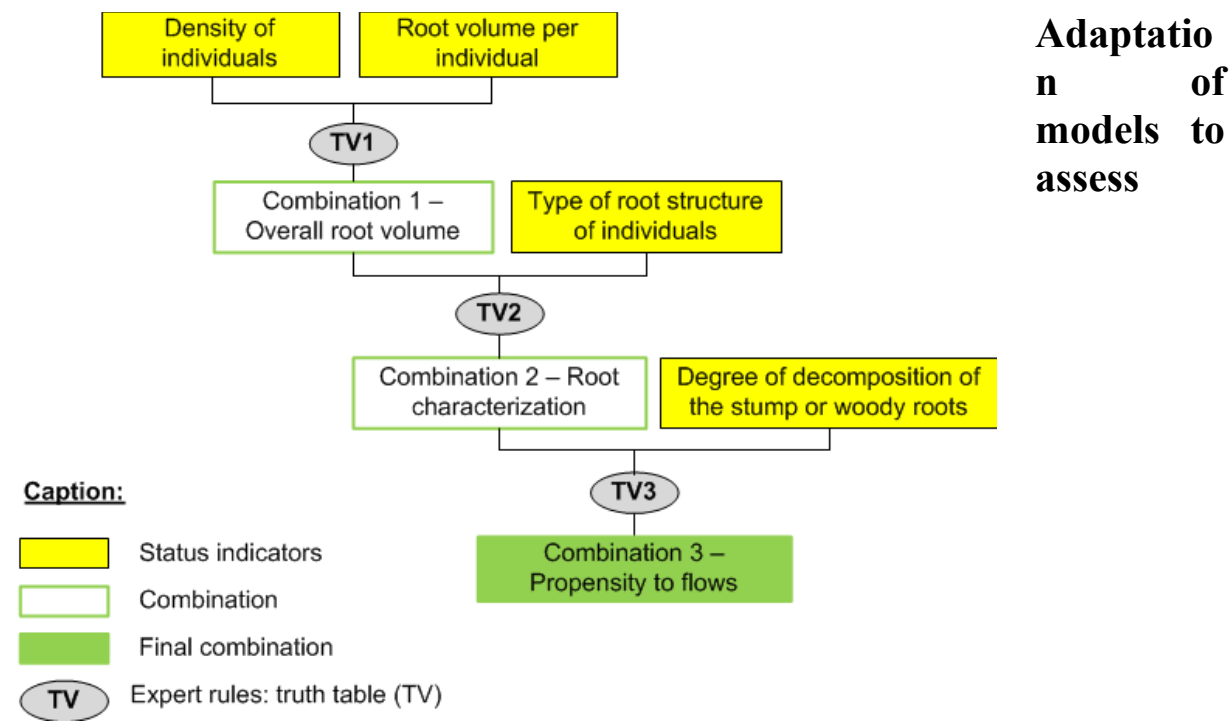

Figure 4. Structure of aggregation for assessing the propensity to flows linked to the presence of woody vegetation on the dam assessed.

\section{performance in abnormal mode}

The originality of our work resides in the capacity of the performance assessment models to adapt to the different cases that can be found, as different combinations of sealing / drainage / monitoring instruments are possible even if they do not conform to the rules of professional practice. Therefore we propose a model in the form of modules that can be assembled to adapt to the dam studied. Each of these modules corresponds to a specific case, a combination of a technical system (sealing and drainage systems) and monitoring instruments (presence / absence of piezometers and drainage flow rate records) and the possible presence of woody vegetation. Therefore we conserved the initial modules of Curt et al (2010) and developed new ones, leading to a total of 27 modules including 11 modules to assess the performance of the embankment dam, making it possible to cover 24 potential cases, 5 modules for the foundation and 11 modules for the embankment-foundation interface. For example, for the embankment we have 4 embankment sealing modules without monitoring (one by type of sealing, i.e. clay facing, etc.); 4 embankment sealing modules with monitoring, 2 drainage modules (if drained), one for the case where the drains are not monitored, the other for when monitoring instruments are present. Lastly, there is one module for the resistance of the embankment dam to internal erosion (Figure 5). The sealing and drainage modules take vegetation into account. The unit "Presence of woody vegetation on the embankment" (cf. Figure 4) is common to all the modules 1-8. The engineer uses the module that corresponds to the dam to be assessed as a function of a decision tree. The number of status indicators varies depending on the type of sealing to be assessed. These 27 modules must be matched with the 40 models required to cover every dam configuration.

Figure 5 presents the decision tree for assessing the "embankment" component. This process is manual at present through we intend to automate it.

The process of modelling through combination is presented in Figure 6 for a homogeneous dam without drains or instruments (module 1 combined with module 11). 


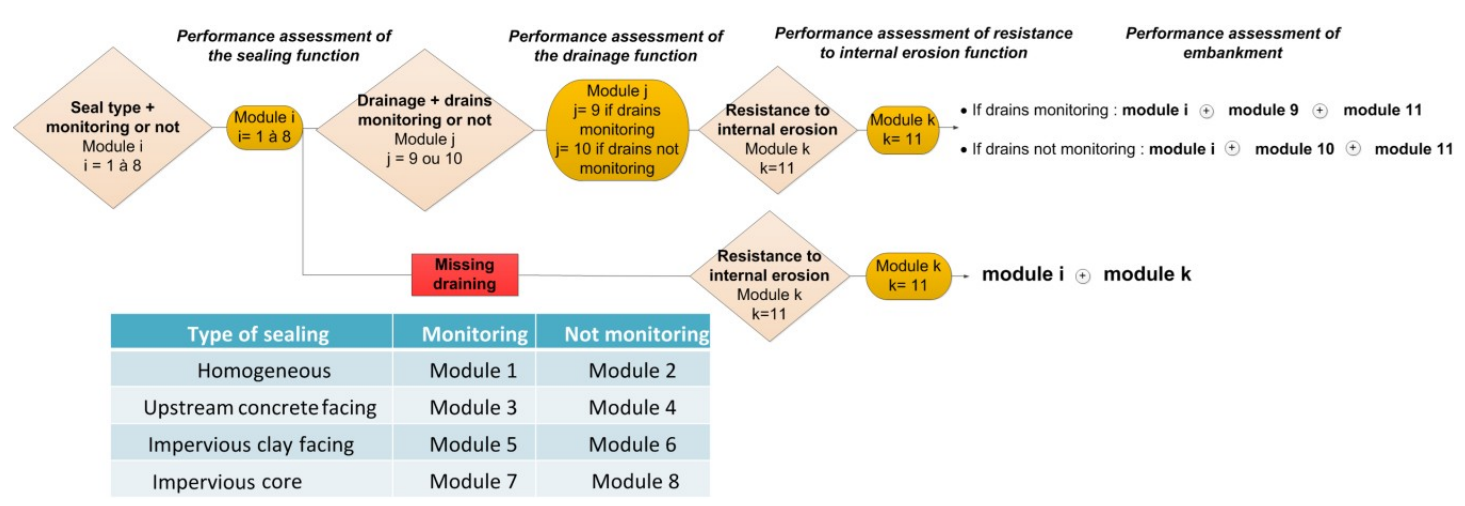

In relation to the initial model in Figure 1, the assessment of the performance of the sealing function is performed according to the following logic: it is obtained directly using the direct status indicator "Leaks or traces of leaks of clear water" if activated (score lower than or equal to 5). Otherwise, it involves status indicators linked to the embankment's intrinsic permeability and those specific to woody vegetation. The information "Propensity to flows linked to vegetation" is aggregated with the indicator "permeability of embankment" related to intrinsic permeability.

The assessment of the performance of the foundation "sealing" function obeys the same logic.

The performance of the sealing function of the embankment-foundation interface is obtained by using the mathematical operator MIN between the performance of the embankment sealing function and the performance of the foundation sealing function. We thus choose the worst score by combining the performances of these two "sealing" functions.

The performance of the sealing function is assessed in order to characterise the potentiality of water being present in the component linked to the characteristics of the materials of the component and/or the presence of vegetation.

Logically, the drainage function disappears in comparison to the initial model.

The performance of the "resistance to internal erosion" function of the component considered (embankment, foundation or embankment-foundation interface) is assessed using the status indicator "Sensitivity to internal erosion". Finally, we combine the values of the performances of "sealing" and "resistance to internal erosion" functions by IF-THEN rules summarised in the form of a truth table defined by the experts (Figure 7). The greater the potential for the presence of water in the component and the sensitivity to erosion increases, the more the score of performance regarding internal erosion will increase and vice-versa. 


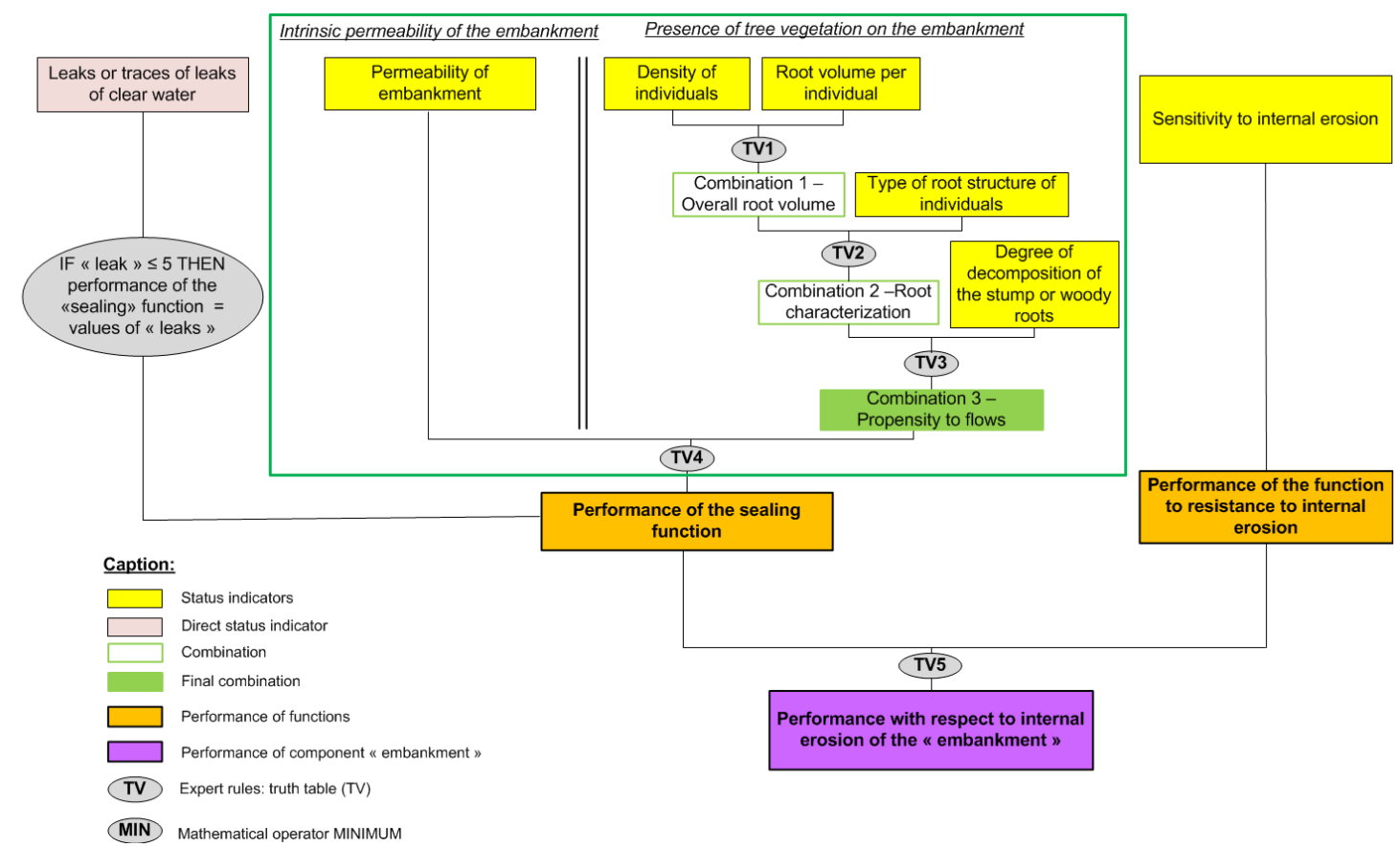

Figure 6. Model of assessment of the performance of the fill of a homogeneous dam regarding the mechanism of deterioration by internal erosion (case of a dam not equipped with drains or monitoring instruments).

\begin{tabular}{|c|c|c|c|c|c|c|c|c|c|c|c|c|}
\hline \multicolumn{13}{|c|}{ Performance the sealing function } \\
\hline \multirow{12}{*}{$\begin{array}{l}\text { Performance of } \\
\text { resistance to } \\
\text { internal erosion } \\
\text { function }\end{array}$} & & 0 & 1 & 2 & 3 & 4 & 5 & 6 & 7 & 8 & 9 & 10 \\
\hline & 0 & 0 & 0 & 0 & 0 & 0 & 0 & 1 & 2 & 8 & 9 & 10 \\
\hline & 1 & 0 & 1 & 1 & 1 & 2 & 2 & 3 & 3 & 8 & 9 & 10 \\
\hline & 2 & 0 & 1 & 2 & 2 & 3 & 3 & 3 & 3 & 8 & 9 & 10 \\
\hline & 3 & 0 & 1 & 2 & 3 & 3 & 3 & 3 & 3 & 8 & 9 & 10 \\
\hline & 4 & 0 & 2 & 3 & 3 & 4 & 4 & 4 & 5 & 8 & 9 & 10 \\
\hline & 5 & 0 & 2 & 3 & 3 & 4 & 5 & 5 & 5 & 8 & 9 & 10 \\
\hline & 6 & 1 & 2 & 3 & 3 & 4 & 5 & 6 & 6 & 8 & 9 & 10 \\
\hline & 7 & 2 & 3 & 3 & 3 & 5 & 5 & 6 & 7 & 8 & 9 & 10 \\
\hline & 8 & 8 & 8 & 8 & 8 & 8 & 8 & 8 & 8 & 8 & 9 & 10 \\
\hline & 9 & 9 & 9 & 9 & 9 & 9 & 9 & 9 & 9 & 9 & 10 & 10 \\
\hline & 10 & 10 & 10 & 10 & 10 & 10 & 10 & 10 & 10 & 10 & 10 & 10 \\
\hline
\end{tabular}

Figure 7. Truth table for combination the values of the performances of "sealing" and "resistance to internal erosion" functions.

When using the models in the field, the assessment is performed on the profile chosen by the assessor as representative of woody vegetation and, if necessary, of other a priori worse profiles regarding vegetation density or presenting a singular aspect (more unfavourable geometry, crossing structure). These results permit orienting the manager towards a more detailed diagnostic that can be zoned around the most unfavourable profiles. So, the goal of our approach is to conduct a first order analysis, showing the occurrence of a degradation or failure. The models do not aim at characterizing the erosion stage. 


\section{Applications}

The performance of 3 Italian and 4 French dams was assessed by using the models developed (Figure 8). Our approach to assessing performance on the basis of combinations of modules as a function of the type of dam to be assessed could be implemented since these applications represented a total of five different types of structure.

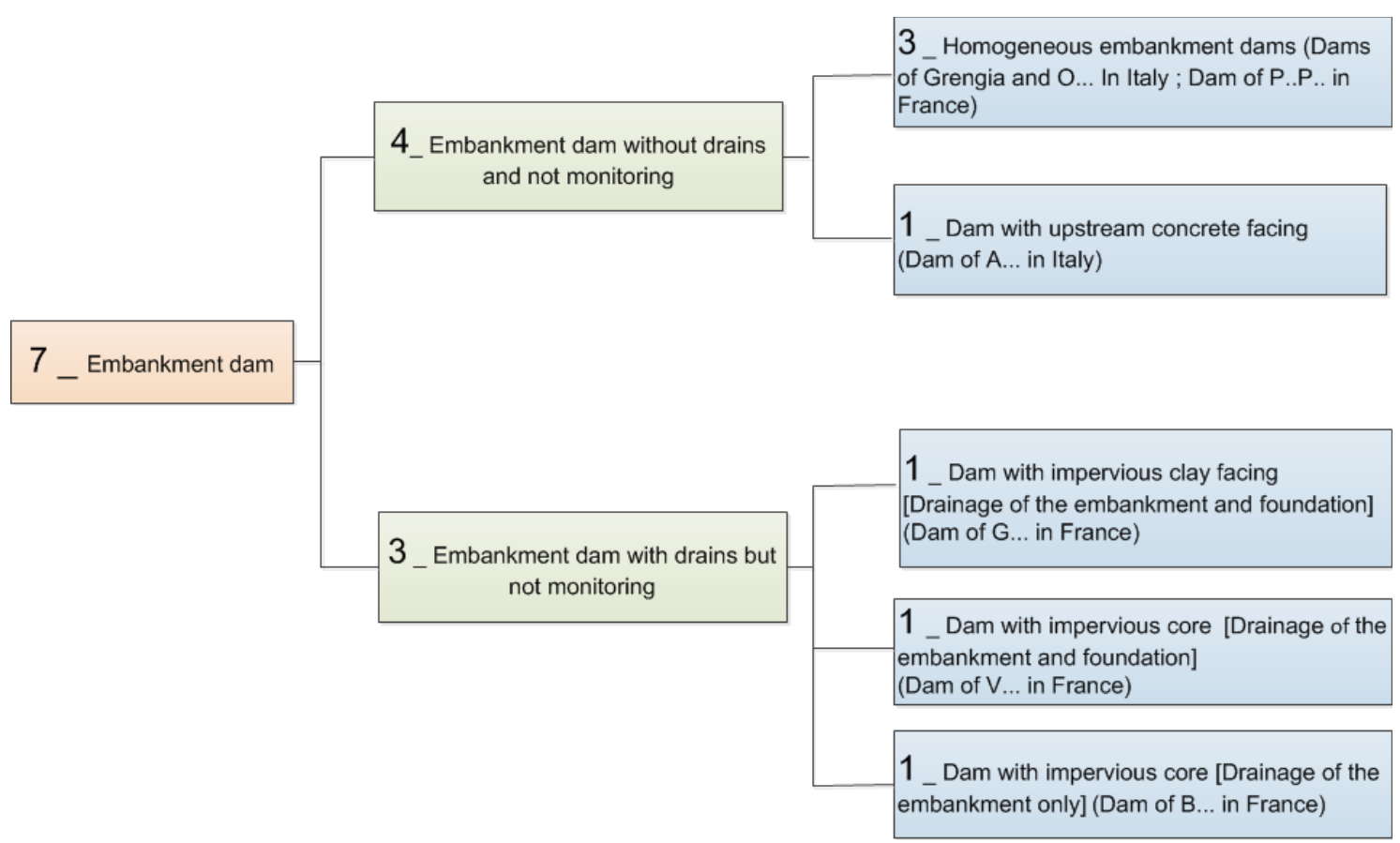

Figure 8. The different types of embankment dams assessed during this study.

We describe the results obtained on the Italian dam of Grengia which, in terms of modules, corresponds to the example of Figure 6. The aim of these exercises was to share the models developed in the trans-border zone. We then present a synthesis of the results obtained for all the 6 other assessments performed.

\subsection{Method}

All the status indicators required to assess performance in terms of the internal erosion mechanism were scored by 3 or 4 engineers expert in dams ( 1 or 2 French engineers and 2 Italian engineers) on site. Usually, only one person is needed to carry out the assessment.

The experts had descriptions of the indicators.

Scoring was done individually at first and then collectively. Only the consensual results are presented here though there is little difference between the scores; the individual scores show good agreement between the experts. The performances of functions and that of the component analysed were calculated by using the model based on the indicators assessed by the experts. In parallel, the engineers were asked to determine a global score without using the model, as this allowed checking its convergence with the opinions of the experts. 


\subsection{Assessment of the dam of Grengia (Italy)}

\subsubsection{Description of the dam}

The Grengia dam, built in 1971, is located at an altitude of about 480 metres. This embankment dam is homogenous and constructed with fill-backfill. It has no drainage system. It is about $10 \mathrm{~m}$ high and has a maximum capacity close to $30000 \mathrm{~m}^{3}$. Since no readings had been taken of the monitoring instruments (piezometers and topographical markers), we considered this dam as being non-equipped. 2 core samples and 2 SPT penetrometric tests performed in 2012 provided information on the stratigraphic constitution of the embankment and its main geotechnical characteristics. Woody vegetation composed of different mature species and stumps cut in 2004 was present on the downstream crest of the structure.

The foundation was fairly sandy due to modification of the bedrock (Gneiss).

\subsubsection{Choice of profile and assessment of status indicators}

After having obtained all the information required from the construction file and the information provided by the owner, a profile 5 meters long, representative of the entire structure and useful for the diagnostic of woody vegetation, was chosen by the group of experts. The width of the crest was $10 \mathrm{~m}$, the downstream slope presented a break in the slope: $80 \%$ at the top, then $70 \%$ at the bottom. There were 3 living individuals, 2 dead ones and 1 sprout of the stump of a tree that had been felled in 2004 . The diameter of the individuals was larger than $30 \mathrm{~cm}$. No leak was observed on the embankment but leaks of clear water were detected at the foundation and at the embankment-foundation interface. To illustrate the status indicators specific to woody vegetation, Figure 9 (a) presents the consensual scores obtained for the status indicators for assessing the performance of the embankment sealing function of the structure (Figure 6). The score of the intrinsic permeability of the embankment proved to be mediocre (score of 5) due to the materials composing it and their compaction. The characteristics of the trees and stumps on the profile led to mediocre and poor scores for the vegetation indicators. Indeed, there was a fairly high density of individuals, with large collar diameters, the key for determining the root types. This showed a mixed root structure including horizontal roots liable to cause leaks. The assessment of the status indicator "Degree of decomposition of the woody stump or roots of an individual" required extrapolation by the experts as we currently possess information on the evolution of the decomposition of roots up to four years of ageing. However, given the good general condition of the stumps of conifers and the considerable sprouting from the stumps of deciduous trees, indicating that they were not dead, the extrapolation determined by the expert on dams and vegetation remained close to the score given in the references established for the status indicator "Degree of decomposition of the woody stump or roots of an individual". Thus, for the woody roots of conifers of mountainous environments cut since four years ago, the references established for this indicator gave a permissible score (6-7), although the extrapolation performed by the expert on dams and vegetation for this specific case led to a mediocre score (5). The current formalisation grid will be completed in the coming years to take into account longer periods of decomposition. 


\subsubsection{Assessment of the performance of functions and performance regarding the internal erosion mechanism}

The performance of the embankment sealing function was calculated by the model by considering, on the one hand, the indicators for vegetation corresponding to the structure in its present state (score obtained: 2), on the other hand, without considering the presence of vegetation by imagining the dam without trees (score obtained: 6). We can conclude that the presence of vegetation significantly degraded the performance of this function, which was considered realistic by the experts. Figure 9 (b) shows the assessments of the performance of different components obtained by the model.

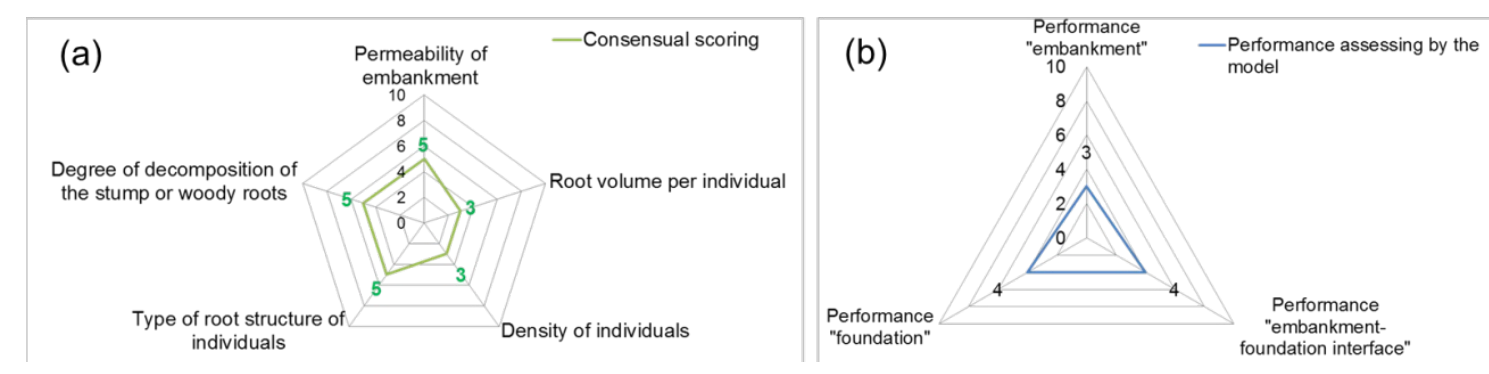

Figure 9. Consensual assessment of status indicators of the performance of the sealing function (a) and the assessment of for the performance of the Grengia dam (b).

It is noteworthy that the performance scores obtained by the model match the opinion of the experts regarding the security of this structure for the internal erosion mechanism.

Finally, the model signalled a poor to mediocre performance. The score of the dam embankment component was worse than that of the interface and the foundation: poor sealing due to the dam's intrinsic characteristics and the presence of large trees, some of which had been cut, making it possible to predict the presence of decomposed roots and thus preferential paths for water; mediocre performance of the resistance to internal erosion resulting from a mediocre assessment of the indicator "Sensitivity of embankment to internal erosion" (resulting from the steep slope of the downstream face). In the case where the woody vegetation may not have been taken into account, the performance of the embankment component would have been mediocre in the same way as for the foundation and the embankment-foundation interface. For the foundation, the mediocre performance resulted in a score of 4 attributed to the indicator "Sensitivity of embankment to internal erosion" due to an admissible gradient (calculated by the experts from the geometry and the material's resistance to erosion) assessed as "mediocre"; and of the "mediocre" performance of the sealing function due to the "clear water leak" observed by the experts when assessing the indicators. Indeed, the presence of clear water leaks is an indicator making it possible to obtain the direct assessment of the performance of the sealing function. If a leak is present, the performance of the sealing function will be mediocre at best according to the formalisation grid established for the status indicator "Clear water leak". This is the case for the dam being assessed given that the clear water leak was not large. For the embankment-foundation interface, the mediocre performance (score obtained: 4) is explained in the same way as for the foundation. These results permit targeting the main weak points of the structure that have to be treated and going to the proposal for corrective actions, such as the treatment of vegetation (extraction of trees and reprofiling of the slope). 
Author-produced version of the article published in European Journal of Environmental and Civil Engineering, 2016,

The original publication is available at www.tandfonline.com

Doi : 10.1080/19648189.2016.1194322

\subsection{Synthesis of the assessments performed}

By way of example, we present scores of status indicators (table 4) and performance results (table 5) obtained for the embankment component for the other applications performed in the framework of this study.

Table 4 gives the consensual scores obtained for the status indicators of each dam (D2 at D7). For D7, the scores of status indicators specific to woody vegetation are given for two profiles (P1 and P2). Depending on the type of dam evaluated (type of sealing, drainage) different types of status indicators are used. 
Author-produced version of the article published in European Journal of Environmental and Civil Engineering, 2016, The original publication is available at www.tandfonline.com

Doi : 10.1080/19648189.2016.1194322

Table 4. Synthesis of the consensual scores obtained for the status indicators of each dam $(D=d a m ; P=$ profile; the text in bold represents the direct status indicators).

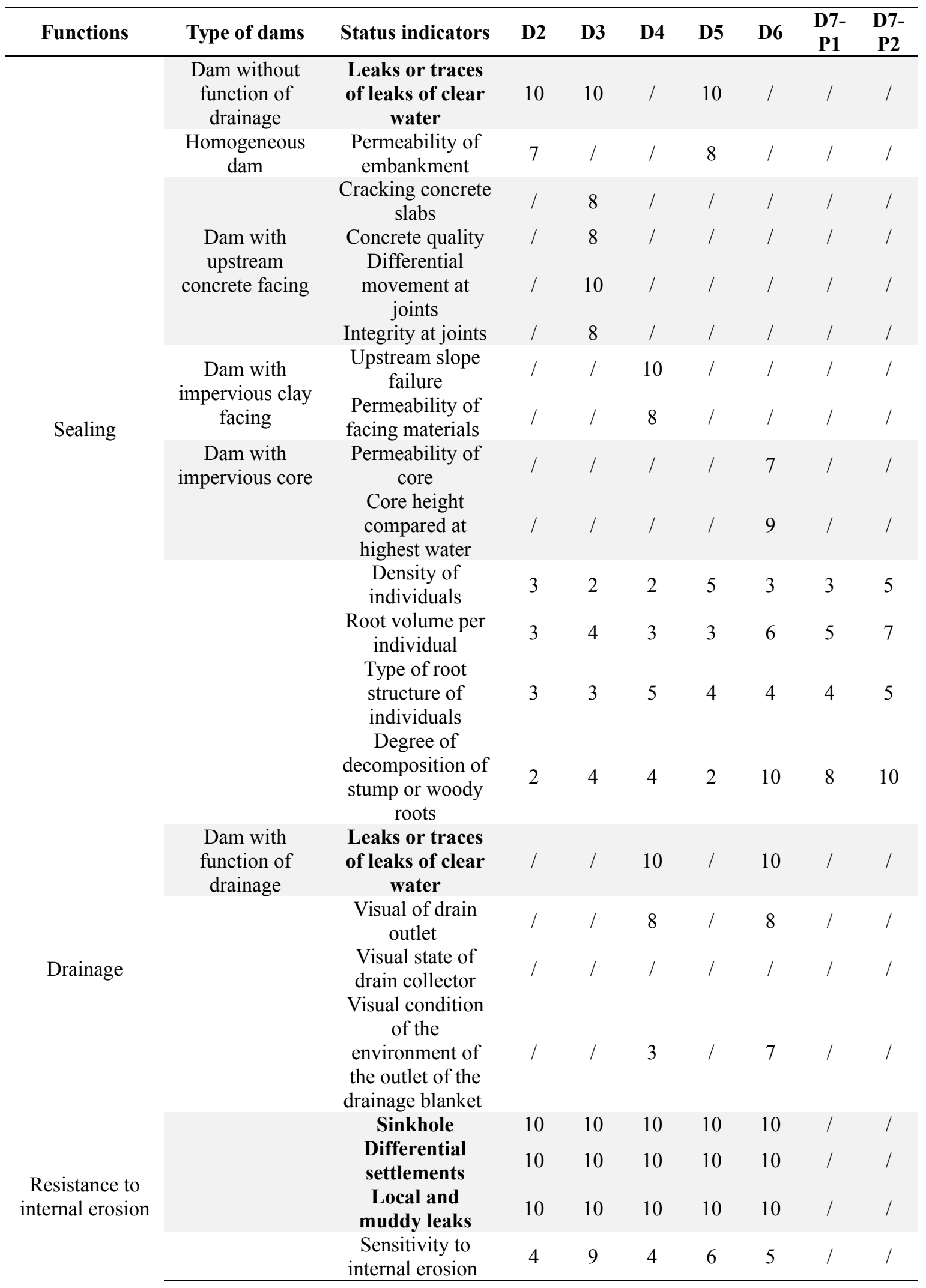


Author-produced version of the article published in European Journal of Environmental and Civil Engineering, 2016,

The original publication is available at www.tandfonline.com

Doi : 10.1080/19648189.2016.1194322

Table 5, the following is given:

- The name of the dam assessed (name and nomenclature: D2 at D7) ;

- The performance of the different functions assessed by the model by considering the presence of woody vegetation and without considering it (for the sealing and drainage functions);

- The performance of the component regarding the internal erosion mechanism by considering woody vegetation and then without considering it.

This approach permits comparing the influence of the presence of woody vegetation on the assessment of the performance of each component of the structure. 
Author-produced version of the article published in European Journal of Environmental and Civil Engineering, 2016,

The original publication is available at www.tandfonline.com

Doi : 10.1080/19648189.2016.1194322

Table 5. Synthesis of the performance assessment results of the functions and "embankment" component of the structures assessed with and without taking woody vegetation into account $[$ Perf. $=$ performance $]$.

\begin{tabular}{|c|c|c|c|c|c|c|c|c|}
\hline Component & $\begin{array}{l}\text { Name of the } \\
\text { dam }\end{array}$ & $\begin{array}{c}\text { Perf. } \\
\text { sealing } \\
\text { (with } \\
\text { woody } \\
\text { vegetation) }\end{array}$ & $\begin{array}{c}\text { Perf. } \\
\text { sealing } \\
\text { (without } \\
\text { woody } \\
\text { vegetation) }\end{array}$ & $\begin{array}{c}\text { Perf. } \\
\text { drainage } \\
\text { (with } \\
\text { woody } \\
\text { vegetation) }\end{array}$ & $\begin{array}{c}\text { Perf. } \\
\text { drainage } \\
\text { (without } \\
\text { without } \\
\text { vegetation) }\end{array}$ & $\begin{array}{c}\text { Perf. of } \\
\text { resistance } \\
\text { to } \\
\text { internal } \\
\text { erosion }\end{array}$ & $\begin{array}{c}\text { Perf. } \\
\text { embankment } \\
\text { (with } \\
\text { vegetation) }\end{array}$ & $\begin{array}{c}\text { Perf. } \\
\text { embankment } \\
\text { (without woody } \\
\text { vegetation) }\end{array}$ \\
\hline \multirow{6}{*}{ Embankment } & $\begin{array}{l}\text { Dam of O..., } \\
\text { Italy (D2) }\end{array}$ & 2 & 7 & 8 & 8 & 4 & 3 & 5 \\
\hline & $\begin{array}{l}\text { Dam of A..., } \\
\text { Italy (D3) }\end{array}$ & 4 & 8 & / & l & 9 & 9 & 9 \\
\hline & $\begin{array}{l}\text { Dam of G..., } \\
\text { France (D4) }\end{array}$ & 4 & 8 & 3 & 8 & 4 & 3 & 8 \\
\hline & $\begin{array}{l}\text { Dam of P..P... } \\
\text { France (D5) }\end{array}$ & 3 & 8 & / & / & 6 & 3 & 8 \\
\hline & $\begin{array}{l}\text { Dam of B..., } \\
\text { France (D6) }\end{array}$ & 5 & 7 & 7 & 8 & 5 & 5 & 8 \\
\hline & $\begin{array}{l}\text { Dam of V..., } \\
\text { France (D7) }\end{array}$ & \multicolumn{7}{|c|}{$\begin{array}{c}\text { Not assessable by the model (not enough information) but assessment of woody vegetation on two } \\
\text { profiles }\end{array}$} \\
\hline
\end{tabular}


The inclusion of the element "woody vegetation" in the models assessing embankment dam performance regarding the mechanism of deterioration by internal erosion makes it possible to improve existing models. It reduces the assessment of the performance of each of the components of the structure as can be seen during the assessment of the performance of the French embankment dam of G...(D4) which changed from good performance when not taking into account woody vegetation to poor performance when taking it into account (Table 5). Taking into account woody vegetation in the assessment models thus permits representing the reality of dams affected by the presence of this type of vegetation and thus increasing their safety regarding the risk of the internal erosion deterioration mechanism. The robustness of these models was verified by the fact that they are capable of reproducing the reasoning of an expert. The procedure used by us during the applications justifies this point as the expert engineers were asked to give a global score for each component of the structure without using the performance assessment model. The results obtained with and without using the model are quite comparable.

The engineers who scored the different status indicators during the seven applications expressed great interest in this method. The use of the formalisation grid for scoring each of the status indicators was explained to them before the beginning of assessment and they found it was easy to implement.

In addition, applying the model to the seven embankment dams allowed the engineers to:

- Check that using the status indicators for assessment was repeatable and reproducible, an aspect strengthened by the fact that some of the engineers were unfamiliar with this type of assessment method.

- Check the formalisations of aggregations of status indicators to obtain the performance of each function. The result obtained by the model had to match the reasoning of the expert.

- Check that using the modular approach in abnormal mode was easy to handle and promising for performance assessment assisted by a model adapted to different types of dam.

Nonetheless, the formalisation of three status indicators had to be improved. For two of these indicators, the differences between the scores of the different engineers were too large, on the one hand because certain engineers had problems in using the corresponding formalisation grid or due to the absence of data. In this case, a better definition was given: this was the case with the status indicator "Sensitivity to internal erosion for the reservoir at normal water level" which permitted assessing the performance of the function "Resistance to internal erosion". On the other hand, data relating to certain status indicators were unavailable, so the model could not be used. Thus the status indicators established previously: "Permeability of material", "Compaction" and "Granulometry" were replaced by a single status indicator: "Permeability of embankment". The latter now allows using the data relating to the permeability of the material, compaction and granulometry without the lack of one of these types of data becoming a constraint. Lastly, the references of the direct status indicator "clear water leak" were modified to make them less penalising according to the condition of the leak observed. This modification in particular was performed following the assessment of the Grengia dam where a score of 3 (poor) would have been too penalising. If the presence of leaks were proven, the score could be 5 at best, i.e. a mediocre assessment. The results were presented with the expert group, allowing us to develop our models in order to perform these improvements. 


\section{Conclusion}

Adaptations and improvements of existing models were performed during this work. These models now permit assessing the performance of embankment dams in a modular way for structures having different characteristics (types of sealing, presence or absence of drainage and monitoring systems); the assessment can also be performed in nominal mode (dam equipped with drain and monitoring system, absence of vegetation) and in abnormal mode (dam not equipped with a drain and/or monitoring instruments and the possible presence of vegetation). The advantage is that it covers a wider range of structures liable to present serious risks for safety given their situation directly upstream of exposed sensitive areas.

The application of these models to real cases demonstrated their robustness, notably by the fact that they are capable of reproducing expert reasoning. It also highlighted the not inconsiderable influence of taking woody vegetation into account on the assessment of the performance of an embankment dam regarding the internal erosion mechanism. These models are now being developed to assess the performance of an embankment dam regarding this mechanism. We intend to continue our works to develop assessment models that will permit assessing the performance of dams regarding other possible deterioration mechanisms: instability (sliding, liquefaction, etc.), external erosion (external erosion by overtopping, scouring).

To improve the models still further, we will take into account imperfections linked to data. To solve this problem several methods could be considered such as the theory of possibilities already employed for dams (Curt, Talon, \& Mauris, 2011).

\section{References:}

Akerkar, R., \& Sajja, P. (2009). Knowledge-based systems. Sudbury, Mass.: Jones and Bartlett.

Andersen, G. R., Chouinard, L. E., Hover, W. H., \& Cox, C. W. (2001). Risk indexing tool to assist in prioritizing improvements to embankment dam inventories. Journal of Geotechnical and Geoenvironmental Engineering, 127(4), 325-334.

Andersen, G. R., \& Torrey, V. H. (1995). Function-based condition indexing for embankment dams. Journal of Geotechnical Engineering, 121(8), 579-588.

Bambara, G., Curt, C., Vennetier, M., Mériaux, P., Zanetti, C., \& Vanloot, P. (2013). Characterization of woody roots located in dykes by near-infrared spectroscopy and chemometrics. In A1 - Agriculture and Environment (pp. 274-279). La Grande-Motte, France.

Booker, J. M., \& McNamara, L. A. (2004). Solving black box computation problems using expert knowledge theory and methods. Reliability Engineering \& System Safety, 85(1-3), 331-340. http://doi.org/10.1016/j.ress.2004.03.021

Chou, S. A., Chen, C. C., Wang, J., Chen, K. ., \& Chen, L. . (2001). A knowledge-based system for dam safety assessment in Taiwan. In Proceedings of Symposium report on the 2nd Worldwide ECCE Symposium "Information and Communication Technology in the Practice of Building and Civil Engineering." Espoo, Finlande.

Curt, C., Peyras, L., \& Boissier, D. (2010). A Knowledge Formalization and Aggregation-Based Method for the Assessment of Dam Performance. Computer-Aided Civil and Infrastructure Engineering, 25(3), 171-183. 
Curt, Corinne. (2013). Combining knowledge-based method and possibility-based approach for the assessment of dam performance. In Dams: Structure, Performance and Safety Management (pp. 1-38). Nova Science Publishers.

Curt, Corinne, Talon, A., \& Mauris, G. (2011). A dam assessment support system based on physical measurements, sensory evaluations and expert judgements. Measurement, 44(1), 192-201.

Deroo, L., \& Fry, J.-J. (2014). Projet National ERINOH - Erosion interne - Approches et besoins en matière d'ingénierie (Rapport de recherche No. LC/10/ERI/68) (p. 212).

FEMA. (2005). Technical Manual for Dam Owners: Impacts of Plants on Earthen Dams. Federal Emergency Management Agency, Us Department of Homeland Security.

Foster, M., Fell, R., \& Spannagle, M. (2000). The statistics of embankment dam failures and accidents. Canadian Geotechnical Journal, 37(5), 1000-1024. http://doi.org/10.1139/t00-030

Laasonen, J. (2013). Risk of the trees and the stumps to the embankment dam safety. Experimental study. Presented at the IECS2013, 9th ICOLD European Club Symposium, Venice, Italy.

Liu, X., Wu, Z., Yang, Y., Hu, J., \& Xu, B. (2012). Information fusion diagnosis and early-warning method for monitoring the long-term service safety of high dams. Journal of Zhejiang University SCIENCE A, 13(9), 687-699. http://doi.org/10.1631/jzus.A1200122

Martinez Santamaria, J. M., \& Fernandez Serrano, R. (2010). Geotechnical impact on small earth dams caused by vegetation growth as a result of inadequate maintenance activity. In Dam Maintenance and Rehabilitation II (CRC Press, p. 1162).

Mériaux, P., Vennetier, M., Aigouy, S., Hoonakker, M., \& Zylberblat, M. (2006). Diagnosis and management of plant growth on embankment dams and dykes. (pp. 1-20). Presented at the Vingt-deuxième Congrès des Grands Barrages, Barcelone.

Peyras, L., Royet, P., Boissier, D., \& Vergne, A. (2004, juin). Diagnostic et analyse de risques liés au vieillissement des barrages : développement de méthodes d'aide à l'expertise. Ingénieries $N^{\circ} 38$, pp. 3-12.

Racoceanu, D. (2006). Contribution à la surveillance des Systèmes de Production en utilisant les Techniques de l'Intelligence Artificielle. Habilitation à Diriger Des Recherches, Université de FRANCHE COMTÉ de Besançon, France.

Su, H., Wu, Z., \& Wen, Z. (2007). Identification Model for Dam Behavior Based on Wavelet Network. Computer-Aided Civil and Infrastructure Engineering, 22(6), 438-448. http://doi.org/10.1111/j.1467-8667.2007.00499.x

$\mathrm{Wu}, \mathrm{Z} .$, \& Su, H. (2005). Dam health diagnosis and evaluation. Smart Materials and Structures, 14(3), S130-S136. http://doi.org/10.1088/0964-1726/14/3/016

Xu, Y., Zhang, L. M., \& Jia, J. S. (2011). Diagnosis of embankment dam distresses using Bayesian networks. Part II. Diagnosis of a specific distressed dam. Canadian Geotechnical Journal, 48(11), 1645-1657. http://doi.org/10.1139/t11070

Zanetti, C., Vennetier, M., Mériaux, P., \& Provansal, M. (2015). Plasticity of tree root system structure in contrasting soil materials and environmental conditions. Plant and Soil, 387(1-2), 21-35. http://doi.org/10.1007/s11104-014-2253-z

Zhang, L. M., Xu, Y., Jia, J. S., \& Zhao, C. (2011). Diagnosis of embankment dam distresses using Bayesian networks. Part I. Global-level characteristics based on 
Author-produced version of the article published in European Journal of Environmental and Civil Engineering, 2016,

The original publication is available at www.tandfonline.com

Doi : 10.1080/19648189.2016.1194322

a dam distress database. Canadian Geotechnical Journal, 48(11), 1630-1644. http://doi.org/10.1139/t11-069

Zwingelstein, G. (1995). Diagnostic des défaillances: théorie et pratique pour les systèmes industriels. Hermès.

Zwingelstein, G. (1996). La maintenance basée sur la fiabilité: Guide pratique d'application de la RCM. Hermès. 